\title{
The repercussions of Covid-19 On the field of education
}

Abdennasser Naji

Amaquen Institute

\section{The evolution of the pandemic and the efforts made to combat it}

Morocco was one of the first countries to take a set of precautionary measures aimed at curbing the spread of the virus, especially when it was found that all the cases discovered were from abroad. The goal was not to allow the virus to infect residents of the homeland by closing the air, land and sea borders. This contributed to reducing the number of local cases, without permanently canceling the occurrence of this matter.

In line with the same proactive policy adopted by the state, several measures have been taken aimed at implementing the principle of social separation, which was mainly manifested in the application of lock-down to citizens. The school, which is attended by about a third of Moroccan citizens, has been closed since March 16, 2020, for fear that it will constitute hotbeds of the virus that are difficult to control. Given that schools represent spaces for heavy gathering for children and adults alike, this may provide an appropriate environment for the spread of Covid-19 in the school population.

According to UNESCO, as of April 21, 2020, 191 countries have closed their schools (Figure 1), with more than 1.5 billion students involved in this measure, which represents $90 \%$ of the total number of learners internationally. As for Morocco, it was affected by the decision to close schools 8.943.156 Moroccan students, which is equivalent to the total of learners at all levels of education at the national level. And like the rest of the world, Morocco has adopted remote learning as a solution to face the interruption of studies in educational institutions, and a special digital platform has been designated for this purpose. 


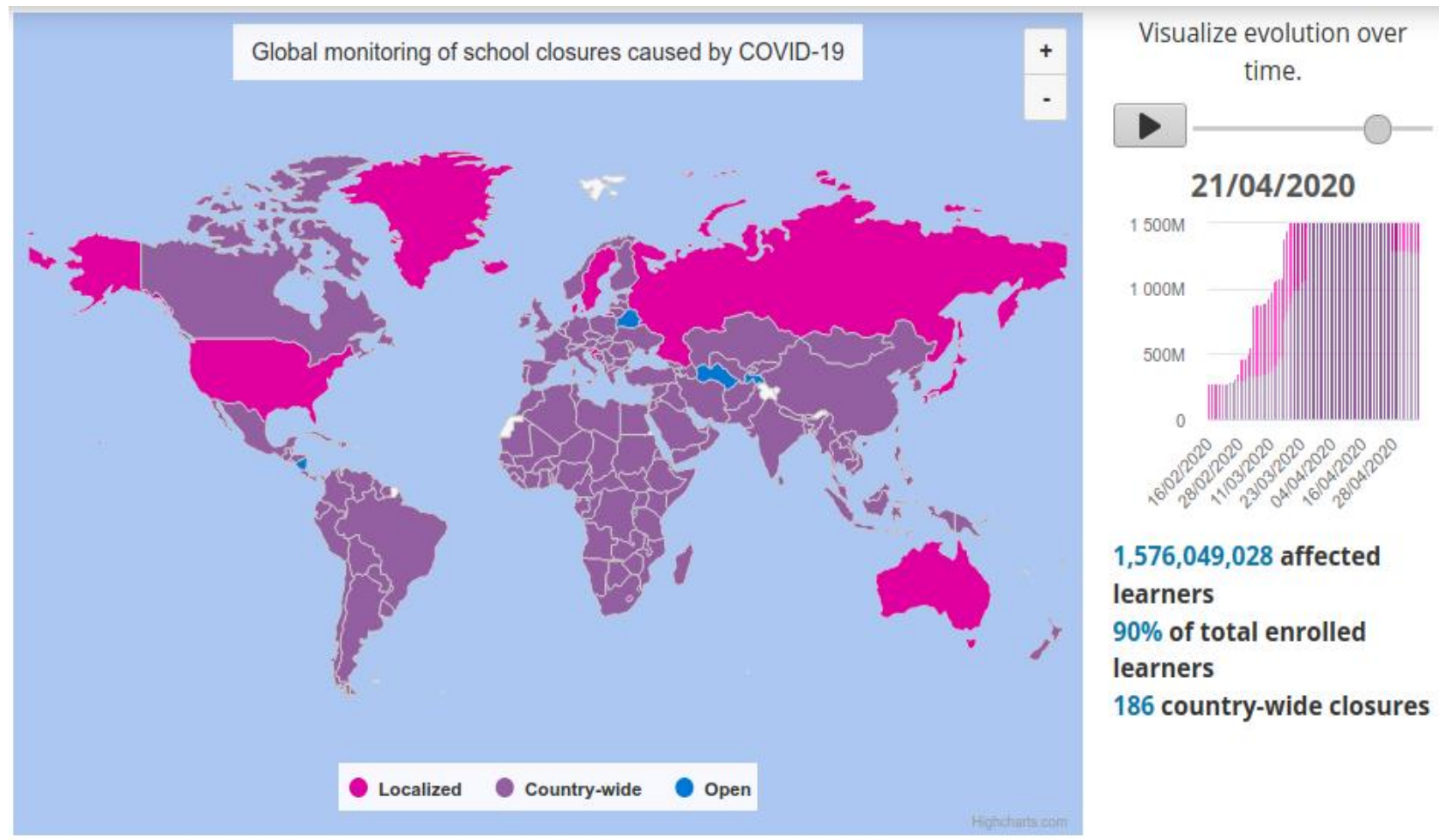

Figure 1: International distribution of school closures due to Covid-19 (Source: UNESCO website)

Returning to the number of visits index, it reached its climax on March 16, 2020, the first day of school closures, with 780,749 visits, after which it was known as a downward trend with fluctuations between ups and downs until it reached its minimum on April 19, when it recorded about 49 thousand visits. If we compare Morocco with other countries that are similar to it in terms of the number of students, namely Saudi Arabia, Peru, Bologna and South Korea, the following observations can be made for the period from March 24 to April 20, 2020:

Figure 2: Comparison of digital platforms in terms of volume of use 5 Total Visits, Last 28 Days (As of Apr 20) $\odot$ Worldwide 1. soutiensco.men.gov.ma epodreczniki.pl $\%$ vschool.sa Q ebs.co.kr perueduca.pe

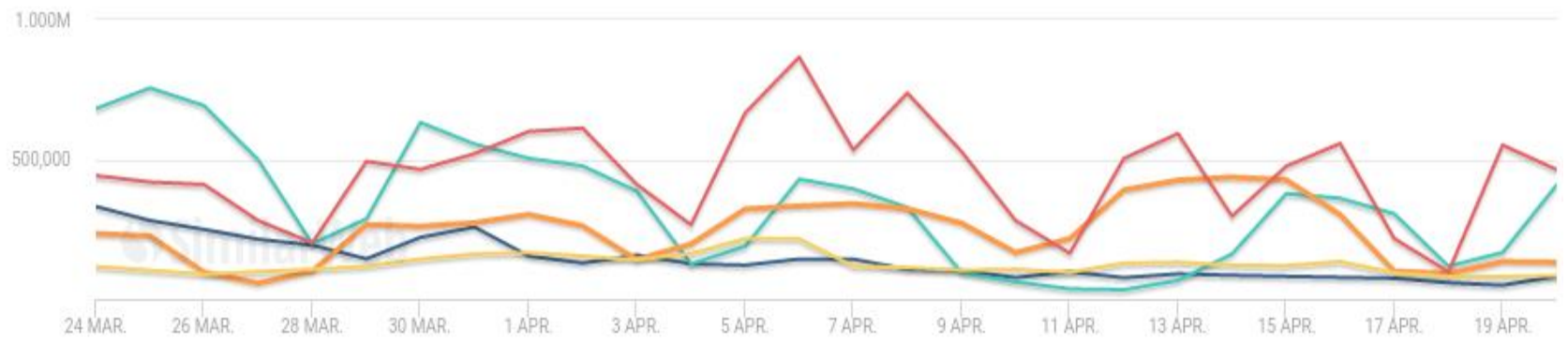


- All countries experienced a near-regular rotation between the days of demand for digital platforms and days of non-attendance, with stability in the general trend of the number of daily visits, except for Morocco and to some extent Peru, who did not record a big fluctuation between peak times and times of abstention, and also knew a decline in the curve of daily visits (Figure 2);

Figure 3: The ratio of the number of digital platform users to the number of upper secondary students

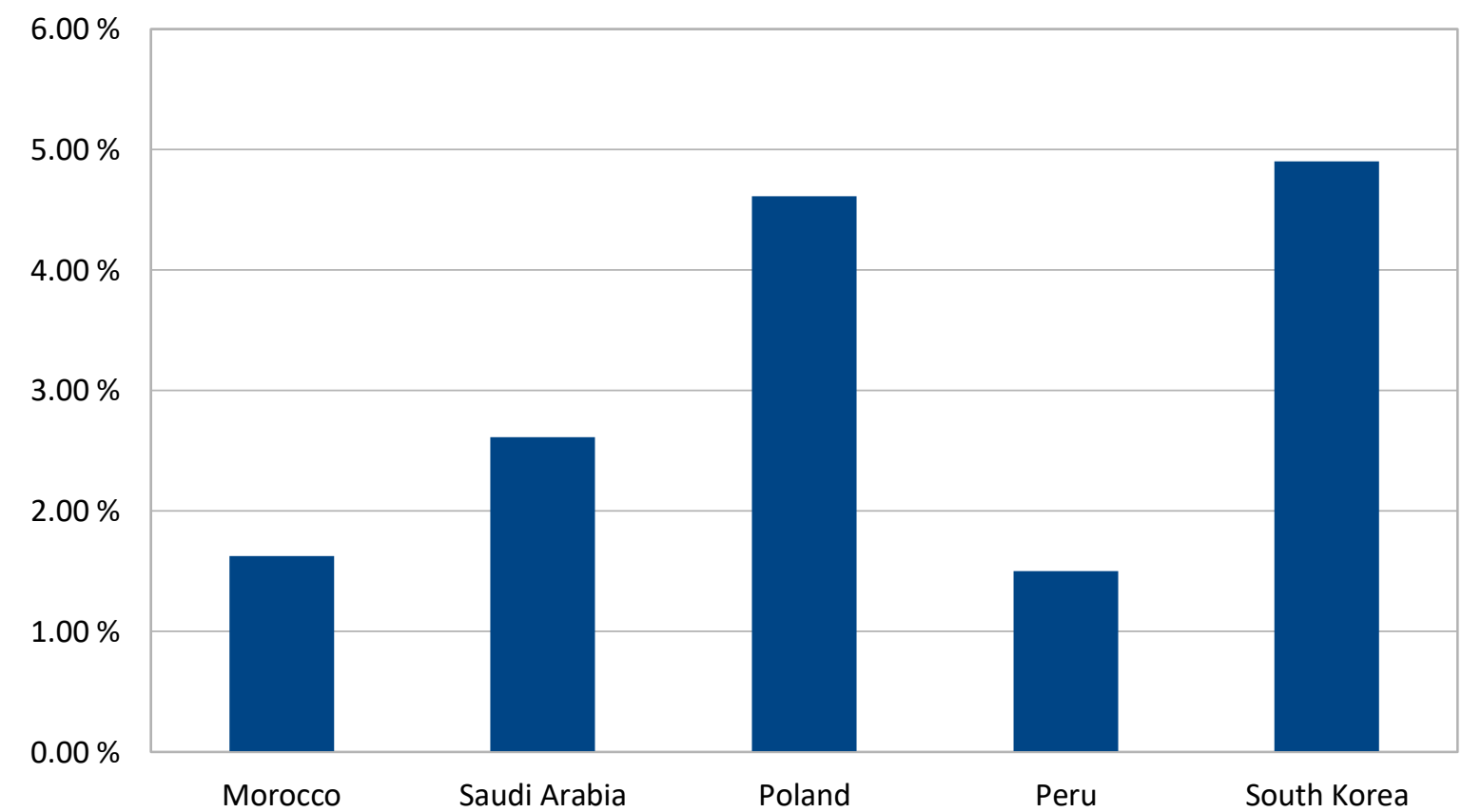

- With the exception of Peru, which Morocco exceeded by about 15 thousand visits per day only, other countries surpassed Morocco in the number of daily visits, with a difference that reached more than 300 thousand compared to South Korea, and about 200 thousand compared to Poland, and 100 thousand compared to Saudi Arabia, so that the number of daily visits in Morocco reached 140 thousand. Since the number of visits represents an average of three times the number of visitors, the Moroccan students who use the official digital platform did not exceed 50 thousand visitors per day, which represents less than $2 \%$ of the students of the upper secondary, and $5 \%$ of the students of the baccalaureate, the same percentage in Peru. This percentage reaches $15 \%$ in South Korea and Poland and $8 \%$ in Saudi Arabia (Figure 3 \& Figure 4); 
Figure 4: The ratio of the number of digital platform users to the number of baccalaureate students

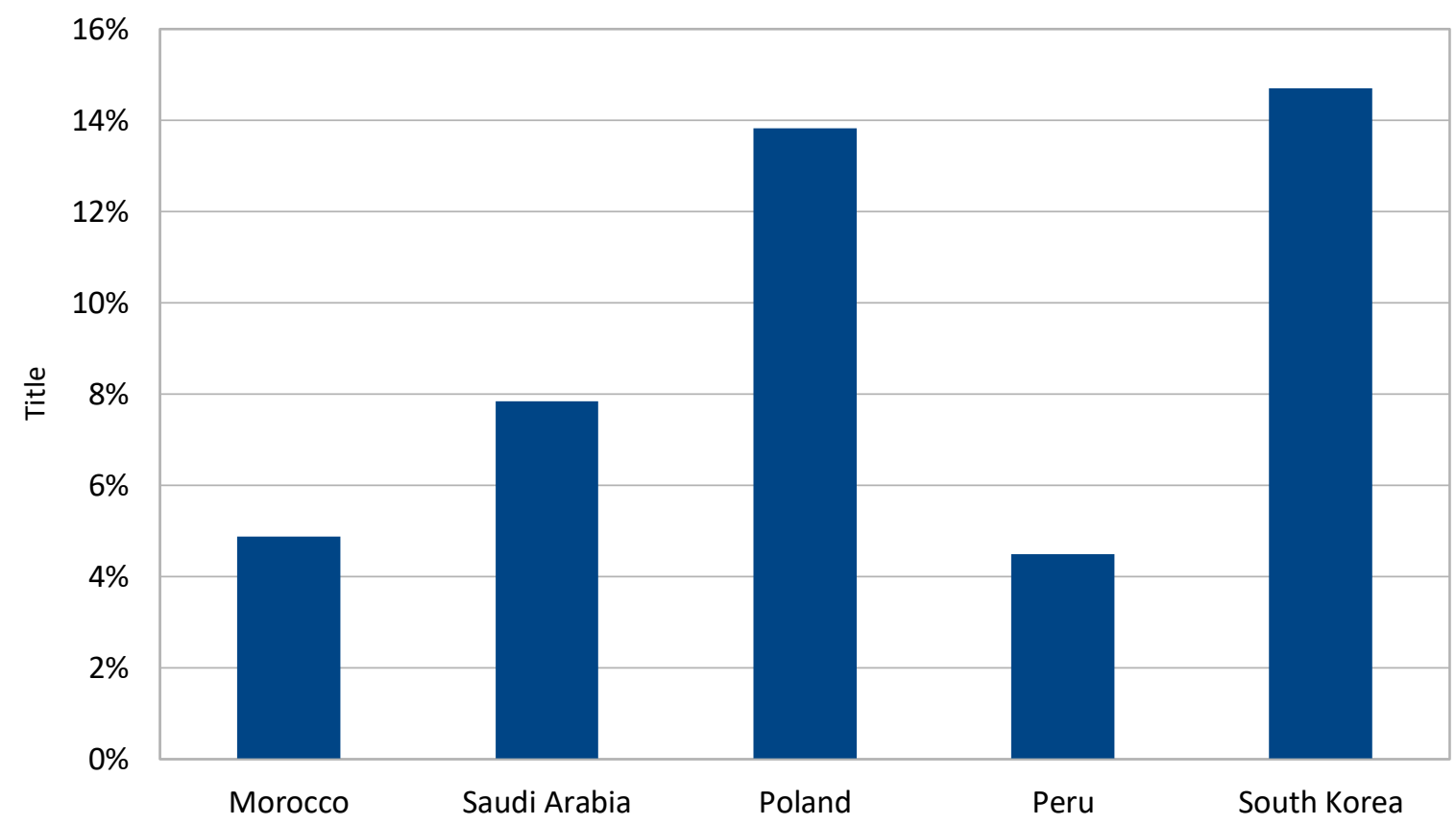

- Most Moroccan students, that is, about 80 percent, use a smartphone to access the official digital platform of the ministry, which is the same trend that exists in Saudi Arabia, while the other three countries use a computer (Figure 5), and this is not an option, but rather it means the lack of computers for about $40 \%$ of Moroccan students (OECD, 2019);

Figure 5: The distribution of the use of digital platforms between the smartphone and the computer
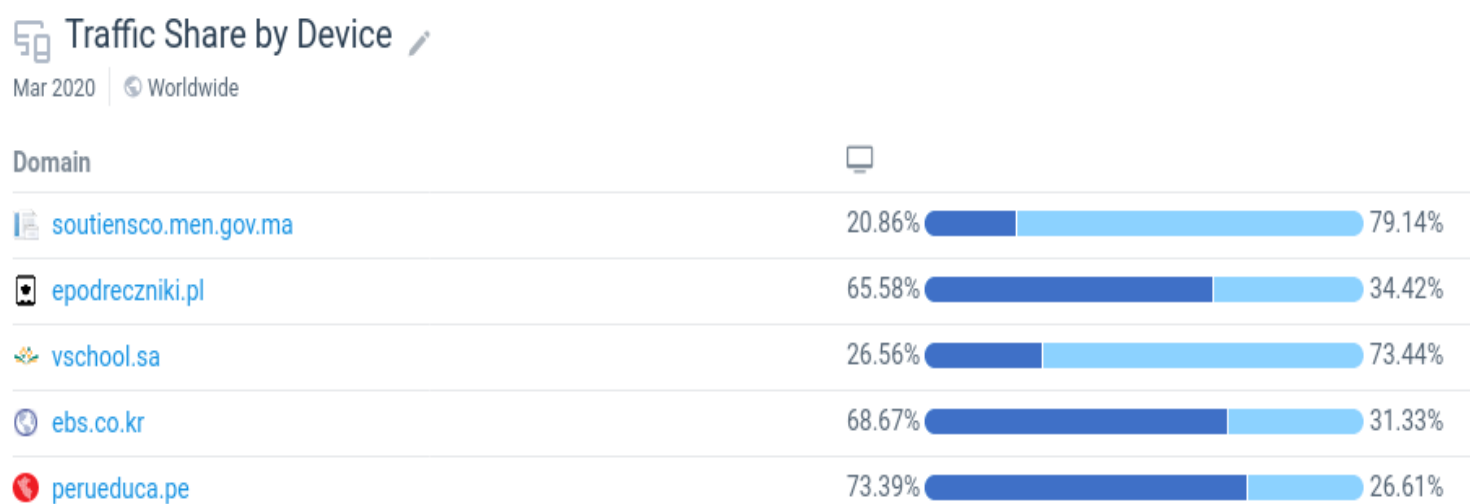

- Each visit to the Moroccan digital platform takes about nine minutes (Figure 6), which means that Moroccan students spend approximately 24,000 hours in front of this platform, which is equivalent to nine seconds per student if we consider that all students, who number up to Eight million, they are supposed to use the aforementioned platform, which is the lowest time registered in all comparative countries (Figure 7). 
Figure 6: Digital platform usage data for number of visits, duration, and pages visited

\section{Engagement Metrics - Mobile \& Desktop}

Last 28 Days (As of Apr 20) $\odot$ Worldwide

\begin{tabular}{|c|c|c|c|c|}
\hline Domain & $\square$ Avg. Daily Visits & ণౌ Visit Duration & Pages/Visit & $Y^{\nearrow}$ Bounce Rate \\
\hline I & 140,033 & 00:09:19 & 5.70 & $33.73 \%$ \\
\hline epodreczniki.pl & 332,962 & $00: 04: 47$ & 5.48 & $57.06 \%$ \\
\hline$\Leftrightarrow$ vschool.sa & 243,748 & 00:13:09 & 21.50 & $27.54 \%$ \\
\hline (2) ebs.co.kr & 451,734 & $00: 07: 48$ & 7.11 & $27.05 \%$ \\
\hline ( perueduca.pe & 125,109 & $00: 20: 16$ & 16.13 & $23.37 \%$ \\
\hline
\end{tabular}

Figure 7: The default daily time period (in seconds) in which a student uses digital platforms

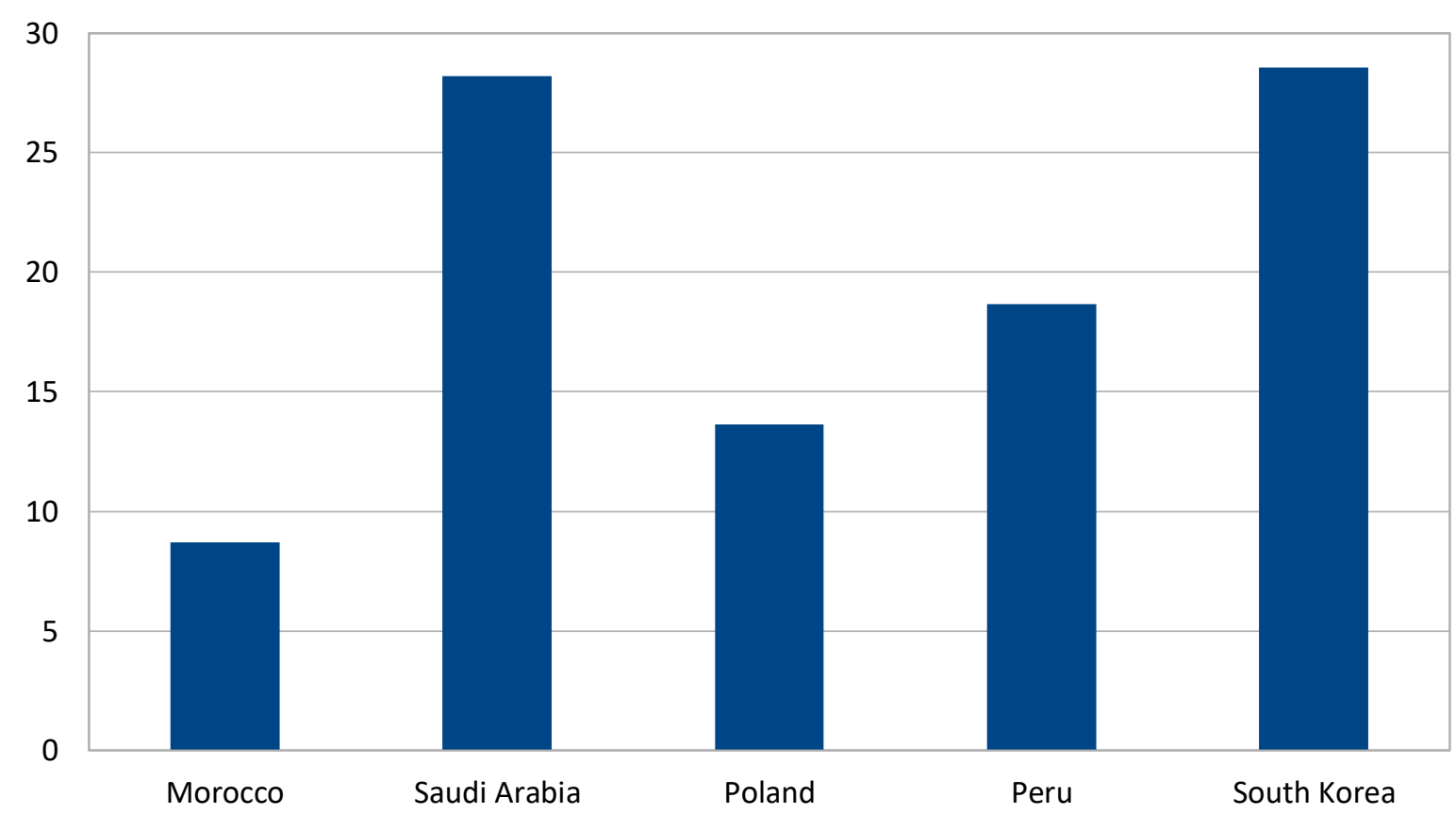

- However, this period of time rises to 28 minutes per pupil, if we consider only the pupils who have already entered the digital platform, which is a period that is less than Saudi Arabia (39 minutes) and Peru (60 minutes), it remains higher than South Korea (22 minutes) Poland (13 minutes). This means that the student generally does not spend more than an hour a day in front of digital platforms devoted to remote education (Figure 8). " In Los Angeles, the nation's second-largest school district, about 13 percent of high school students have had no online contact with teachers since schools closed three weeks ago, and onethird are not regularly participating in online learning, according to the superintendent, Austin Beutner." (Coronavirus schools attendance absent, 2020). 
Since students use other methods of remote learning, especially social media tools, it can be said that the time spent on academic achievement may be longer than indicated by the statistics resulting from the analysis of data access to digital platforms ${ }^{1}$. However, these means remain unauthenticated by the Ministry and are not exclusively dedicated to learning, something that may cause side effects on the learner, which may be disastrous, without necessarily achieving the desired returns on the quality of learning.

Figure 8: The length of time a student spends on digital platforms in each country

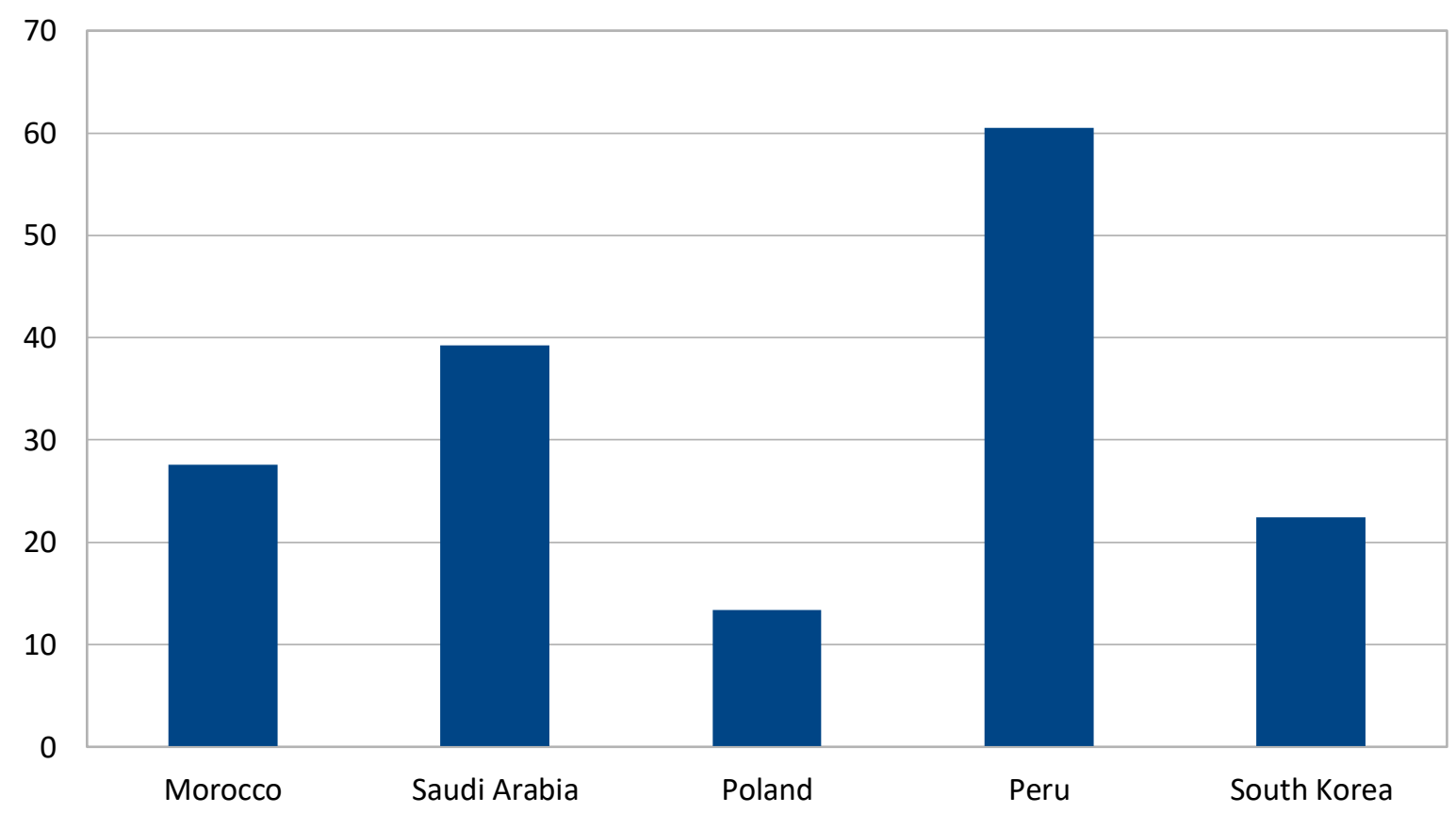

\section{Assessing the consequences of the pandemic at the national level}

The state has played great roles in confronting the pandemic and mitigating its repercussions at the health, economic and social levels. Thus, Morocco was able to besiege the virus and reduce its spread among the population. He also approved several economic measures to help companies overcome the crisis with the least possible damage, and granted financial assistance to people who lost their jobs due to the pandemic, especially those working in the informal sector. 
In the field of education, the Ministry of National Education has made an exceptional effort to adapt to the situation of forced discontinuation of studies due to the Corona pandemic, which was to provide digital resources for learners that were mainly video lessons that enable the student to continue his learning remotely. And without being drawn behind the ministry's over-enthusiasm, which led it to claim that what was produced in ten days exceeded what the ministry produced in ten years, because that condemns the ministry itself, which during this period was unable to achieve the digital boom that was promised by a program developed for this purpose, within the framework of The Morocco Digital Project, it was called the GENIE Program.

This Program has acquired $90 \%$ of the digital resources appropriate for national study programs, according to the Ministry of National Education, with a financial cover of 53 million dirhams, and $87 \%$ of educational institutions were equipped with a minimum of multimedia equipment, with a financial cover of 635 million dirhams (ONUTICE, 2020). Also, the annual study carried out by the Ministry (Ministry of National Education of Morocco, 2018), confirms that most teachers (75\%) incorporate digital resources and tools into their pedagogical scenarios, but without real feasibility of pedagogy. Because the same study admits that $77,7 \%$ of inspectors admit that teachers find great difficulties in integrating and using information and communication technology in teaching their subjects.

The state spent in a GENIE program in ten years about one billion dirhams, in order to equip educational institutions with computers, train teachers in information and communication technology, and produce or acquire digital resources. But this was not reflected in the hoped-for form of the Moroccan educational system. The first goal of the GENIE program, which is to use informational methods in educational institutions, was not achieved, so that: "The average duration of use per student reached only 18 minutes per week in primary, lower secondary, and upper secondary education, and this rate is much lower compared to the goals set, which are respectively one, two and three hours for the three levels (Cour des comptes, 2014)". In the area of digital 
resources, program managers preferred "the acquisition of high-cost proprietary software, rather than an incentive to use free software and open source systems" (Cour des comptes, 2014).

This apparent failure to achieve the goals of the Morocco Digital in the field of education, was approved by the Ministry recently when talking about the digital boom that it achieved in the time of Corona in a way that has not been achieved for ten years. However, this failure should not be covered by the reported exaggerated statistics about remote education ${ }^{2}$, which, in addition, do not reflect the reality of students and teachers dealing with a new system of teaching and learning, it does not say anything about the question of the quality of the product offered on the digital platform, which is made mostly of Videos. Especially since the answer to this question is related to the answer about what pedagogical methods are adopted in remote education proposed by the ministry, and the extent to which teachers are able to competence in digital pedagogy, as well as their ability to technical competencies required by remote learning. These are all competencies gained by practice, but the reality of the situation in our schools, including those distinguished and those belonging to the private sector, clearly shows that the use of digital education remains the exception that affirms the rule, which is the dominance of traditional pedagogical practices.

On the other hand, and due to the lack of the necessary remote learning requirements, especially the computer and the smartphone, among all students, especially the inhabitants of villages and remote districts, the question of "educational" inequalities remains urgent in this difficult circumstance. Even in the presence of television channels, which also took on the task of broadcasting video lessons, for the benefit of learners. Although the Ministry made a commendable effort to secure the daily broadcast of about 60 video lessons on its TV channels, this is not sufficient to ensure educational equity among students, regardless of the economic, social and spatial differences they suffer from. In addition, learning is a complex process in which several factors overlap, which are

${ }^{2}$ The Ministry's communication about remote education dated April 2, 2020 announced 600,000 daily users, which is a number far from the statistics issued by websites specialized in monitoring the size of access to digital platforms. The same communication referred to the production of 3000 digital resources as an unprecedented event, while previous communications to the Ministry, dating back to 2012, confirmed the provision of sufficient digital resources to all students. 
difficult to control by reducing it to just a one-way relationship, between a deaf machine and a child that is full of vitality and activity, and necessarily needs someone who directs and guides, in order to benefit adequately from the remote learning process.

It is true that the Ministry tried to rectify the situation by pushing the institutions to create virtual classes based on the "TEAMS" application ${ }^{3}$, which was originally integrated into the MASSAR system, but everyone knows that the problem lies in the proper use of this application, and similar applications. This is a question closely linked to the ability of teachers to appropriate digital and pedagogical skills. Aware of this problem, the Ministry launched a remote learning portal for teachers, called "E-Takwine", but it seems that the demand for this training has not reached the required level. Thus, the statistics on access to the aforementioned site show that the number of daily visits does not exceed on average two thousand, with the absence of teachers from this site over several days (Figure 9), and an average hourly consultation not exceeding eight minutes per visit.

Figure 9: Limited demand for the Ministry's official website devoted to distance training in information technology

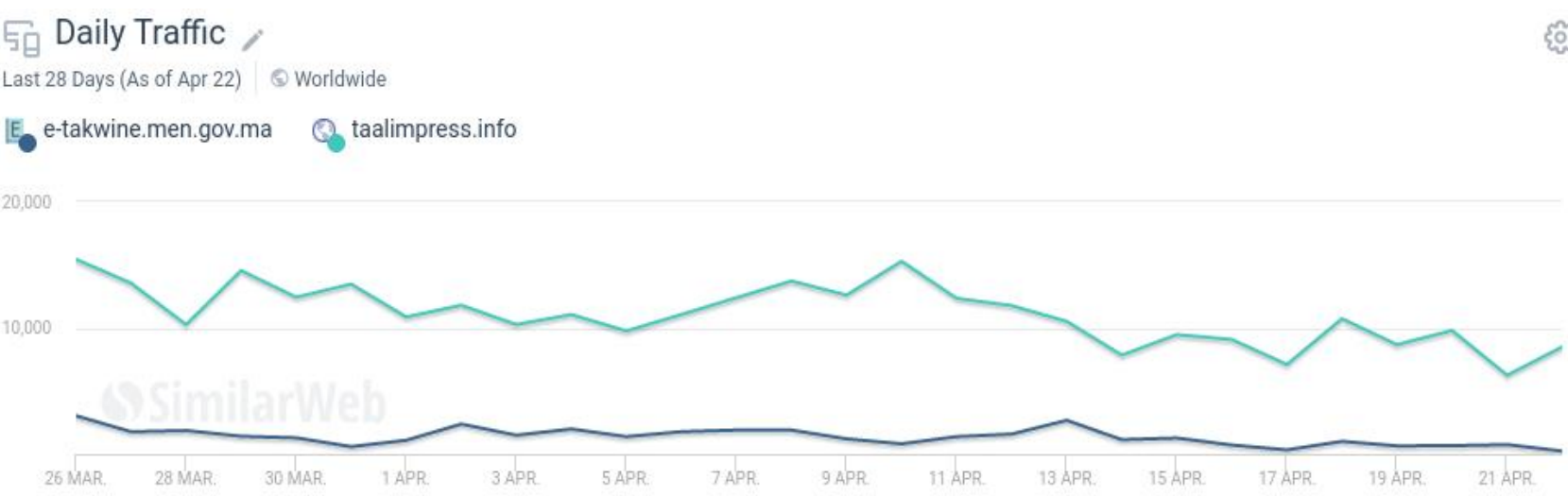

In the face of the apparent lack of training and digital resources, educational and administrative actors made great efforts to provide the minimum required for the rotation of the remote education

${ }^{3}$ In its communication to April 2, 2020 about remote education, the ministry indicated that the number of new virtual classes was 400,000 , but the number of users did not exceed 100,000 , according to the text of the communication itself. 
wheel. But it was certainly not time to allow the necessary attention to be given to the qualitative aspect, something that inevitably reflected the quality of the product offered to learners.

Besides the specialization in the training of teachers that will not help the remote education initiative achieve many of its goals, it does not seem that the Ministry's commandment bet on the involvement of parents will bring a lot of support for this huge and unprecedented project, neither nationally nor internationally. Even if we assume that the educated group of these will do their utmost to keep up with their children and track their academic achievement from a distance, the uneducated group will not be able to carry out these tasks even if they lack the will.

In the absence of accurate statistics about the effect of remote education on the academic achievement of Moroccan students during the lock-down period, some international studies conducted in other countries, which outweigh Morocco's experience and capabilities in the field of digital education, can be useful in confirming some of the conclusions previously mentioned in this paper. In a study released on April 20, 2020, conducted by the British Public First Foundation for the benefit of the Sutton Trust on a sample of British families, we find many conclusions that do not need much effort to drop on the Moroccan case, considering the difference in capabilities and qualifications. The following are the most important summaries of the British Study (Covid-19 and socia mobility impact brief, 2020):

- A third of pupils are taking part in online lessons while schools are closed. However, at private schools, $51 \%$ of primary and $57 \%$ of secondary students have availed of online lessons every day, twice as likely as in state schools.

\section{- $60 \%$ of private schools and $37 \%$ of schools in the most affluent areas had an online} platform to receive work, compared to $23 \%$ in the most deprived schools. $45 \%$ of students had communicated with their teachers in the last week. At independent schools, the figure is $62 \%$ for primaries and $81 \%$ for secondaries. 
- Despite the challenges faced, parents are overall positive about schools. $61 \%$ of children learning at home had parents who were satisfied, similar to $65 \%$ of those who are still in school as their parents are keyworkers.

- The home learning environment is likely to play an even more crucial role as most learning is now done in the home. More than three quarters of parents with a postgraduate degree, and just over $60 \%$ of those with an undergraduate degree felt confident directing their child's learning, compared to less than half of parents with A level or GCSE level qualifications.

- Some inequalities are reflected in the amount and quality of work being received by teachers. $24 \%$ say that fewer than 1 in 4 children in their class are returning work they have been set. $50 \%$ of teachers in private schools report they're receiving more than three quarters of work back, compared with $27 \%$ in the most advantaged state schools, and just $8 \%$ in the least advantaged state schools.

\section{Urgent measures to get out of the crisis}

Once we have gone through this crisis, thank God, and no matter what the statistics are on the number of people who have actually benefited from the remote learning process, everyone will agree that a hastily installed system in an environment not accustomed to this teaching method, will have a low impact on the quality of learning, if not negative. If we add to this the differences that we noted between the learners in the volume of the courses followed at a distance, the principle of equity requires that what is implemented within the framework of remote education be considered only as a "review of lessons" made by some students.

This means that the period in which schools were closed is also a period for the suspension of studies, and they should be resumed at the point where they stopped on March 16, 2020. Otherwise, it will be a repetition of the same approach taken by the Ministry in the case of medical students, and the case of contracting professors, when the whole year was reduced to three months of training were deemed sufficient to announce their success. 
Also, the Ministry's failure to rely on any system to evaluate academic achievement throughout the lock-down period will not enable teachers to know the extent of school achievement for students. Therefore, it is impossible to continue studying based on what the learners got during the closing of schools, because it is simply not clear-cut.

Under these circumstances, the question of the fate of the current school year remains open. Of course, the efforts of two-thirds of the school year cannot go unheeded just because of the stumbling in the academic achievement in the last third, knowing that on a practical level, the study actually ends at the end of May at the latest, something that reduces "learning disorder" to two or a month and a half.

So, should we go towards canceling the certification exams as most countries did, or do we consider them as sacred things that should not be compromised, especially when it comes to the baccalaureate degree. Even France, from which we inherited this certificate with all its organizational complications and social and psychological burdens, decided to cancel the final exam that leads to its achievement, and only to calculate the marks of continuous monitoring. On the other side of Latin Europe, England followed another path, though it also canceled the certification examinations, but decided to adopt a complex rule to determine the level of the student based on all the assignments and works he accomplished, in addition to his institution's estimates about the marks that he could have obtained If the exams took place normally (Murphy \& Wyness, 2020). In order for the process to be more equitable for the English pupils, it will be available for those who saw that the estimated marks do not reflect its true level, to pass the certification examination when schools open.

Of course, each country has its own peculiarities, but even if we assume that Morocco will emerge from the crisis at the end of the second period of quarantine, that is, on May 20, 2020, and that it will follow the steps of countries that gradually returned to their normal lives, it is likely that the baccalaureate students will return to class again in the second week of June 2020. According to what we went to in this paper of not achieving remote education for its goals, we see the necessity 
of extending the school season for at least another month, devoted to completing the curriculum and supporting struggling students.

This means that the baccalaureate exams can only be taken at the end of July. If we count the time that should be allocated for the correction, the announcement of the results of the normal session, then the passage of the remedial session, the correction of its copies and the announcement of its results, we will have arrived at the end of August, and we will therefore have consumed the whole period usually reserved for summer holidays. This is a practically impossible solution, unless there is a desire to postpone the next entry to school and university until November, and to allocate the months of September and October to complete this year's program, and conduct its certification exams. But this formula also comes up against an educational and pedagogical constraint, linked mainly to the summer holidays, and the erosion of the resulting school balance, which requires an additional effort to bring it back to the level it was before the holidays.

Therefore, and without recommending the success of all students, as some countries have done, because this "solution" is only an export of the problem to next year, the English solution remains the closest solution equity. Thus, it considers the marks obtained by the students during the school year, or what is called continuous monitoring in France, and gives the right to the pedagogical managers of the school to assess the level of the student, depending on the requirements of the certification exam. To this, we can add, if technological solutions allow, an oral test for each student, which will be carried out in the subjects of the final exam, and whose score will be counted in the student's final average. Consequently, for the baccalaureate, we suggest that the regional examination retains $25 \%$, the continuous monitoring $25 \%$, the estimates given by the school officials $25 \%$, and for the oral test $25 \%$ as well.

Whatever the solution that the Ministry will adopt, this is an appropriate opportunity to review the academic evaluation in general, and the certification examinations in particular, including the baccalaureate exam. This "educational monster", which constitutes a real obsession with students and families every year, while its value in higher education is less than that it has all this prestige. It 
is also an opportunity to prepare for the next academic season, in a manner that considers the new reality of the school as imposed by the Corona pandemic, and considers it just a first link in a series of measures aimed at thinking about a new school. This school is based on the appropriate application of the framework law for the system of education, training and scientific research first, and the strong evocation of remote education and digital technologies as a determining factor in the new vision of education.

\section{Formulating new policy approaches to address impacts and prepare for shocks}

The remote learning experience will result in two contradictory scenarios, according to the results of the experiment. The first scenario is linked to its success, and in this case, there will be a feeling among all parties concerned, especially the student and the teacher, of the importance of remote education and the positive role it plays in serving the quality of learning and meeting educational and pedagogical needs of learners, and thus the fundamental question about the necessity of the school in its traditional sense in a world will be raised Digital technology par excellence. As for the second scenario, it is related to the failure of the remote learning experience, in which case the school will be seen in its current form as an indispensable refuge for both the teacher and the learner, as long as the alternative that we presented to them was disappointing for both of them.

But whatever our assessment of the experience of remote education, what we have lived through in the quarantine period, educational actors, administrators and families, requires thinking about the school from a new perspective, not dependent on the constraints of the stage, which remains objective linked to the occurrence of an emergency that no one expected. Rather, it evokes the great opportunities offered by learning outside the narrow walls of the school in its classical sense, but without permanently canceling it, because it remains one of the foundations of the educational learning process, which cannot be done in an appropriate manner except by relying on it.

This is because learning is a human process that can only be achieved through interaction between the teacher and the learner on the one hand, and between the learners among them on the other 
hand. A face-to-face interaction filled with human feelings and associated with educational aspects based on the principle of education on values. This cannot be compensated for by any virtual interaction, no matter how sophisticated it is. This new perspective cannot, from our point of view, deviate from the three pillars that remain necessary to build a new school, which looks to the future with broad hopes that allowed the positive interaction of Moroccans, state and society, with a pandemic that upset many scales and shaken many axioms.

The first pillar of the human element: if interest in the human element in terms of training and motivation remains one of the bases for improving the quality of education, the pandemic has shown us above all that man as a person who embodies the symbols of duty and sacrifice must henceforth be above all consideration. There are among the doctors and nurses who sacrificed themselves to save those infected with the virus, and among the officials who put the interests of the homeland and the citizens before his personal interests, and the same goes for all professions that were at the forefront in the face of the pandemic, including teachers who have made the maximum effort to guarantee the appropriate learning of their students, thanks to daily monitoring via available social media.

All this is true, but it is also true that some of them preferred to escape duty or did not do it properly, including certain educational and administrative actors. The new school after Covid-19 cannot be based on a structure supported by a human soul empty of noble human principles. Therefore, the first pillar of the construction of this school is to build the right person, and establish a monitoring and support system to continually remedy any dysfunction in this building. At that time, the value of the teacher in society will increase, and he will become a hero in the eyes of the citizens "applauding him from the balcony of the houses enjoying their work, as they do today every night with health professionals." (Bouvier, 2020).

The second pillar of digital technology: If all educational systems in all countries claim to have reached advanced levels in the application of remote education, with a difference in size and scope, then the Corona pandemic confirmed that these are just allegations, some of them are false and 
some of them fell into the trap of exaggeration. But it is objective to say that no country has previously experienced remote education as widely as it did obligate today, and therefore all of the country was not prepared for this unprecedented global event, so it was natural for deficiencies to appear. This crisis, especially since the possibility of its recurrence is very likely, according to scientists, has ensured the certainty that digital technologies are an integral part of the future of education, and whoever does not take it into account in its educational policies will pay a heavy price in the future.

Teachers, administrators and parents have noted many positive points about digital learning, and this positive credit will need to be built on in the future. In terms of differentiated pedagogy, for example, which teachers know is inaccessible in the classroom, especially when it is crowded with students, but digital technologies make it really feasible. In monitoring and evaluation, and the enormous potential of these technologies in terms of formative assessment, monitoring and support, and fix of learning difficulties. As well as at the level of continuous communication with families, involving them in the learning of their children and in the continuous monitoring of their studies.

The third pillar of public school: Since globalization has dominated all vital areas, the world has witnessed a tendency to adopt privatization, even in the field of education. While no one disputes the importance of the private sector and the services it provides, which contribute to wealth creation and development, many researchers and experts have shown the negative impact of private sector development on the principle of equity and equality, especially in the social fields, including the education sector. The Corona pandemic revealed differences between pupils in public and private education, whether in terms of access to remote learning or the quality of this learning. This raises the question of public school and the need to upgrade its place in any future education system. 


\section{References}

1) Bouvier, A. (2020). COVID19 : il faut préparer le monde pédagogique post crise. la Mission lä̈que française.

2) Coronavirus schools attendance absent. (2020, 05 05). Retrieved from New York Times: https://www.nytimes.com/2020/04/06/us/coronavirus-schools-attendance-absent.html

3) Cour des comptes. (2014). Evaluation de la stratégie MAROC NUMERIC 2013. Cour des comptes.

4) Covid-19 and socia mobility impact brief. (2020, 04 26). Retrieved from suttontrust: https://www.suttontrust.com/our-research/covid-19-and-social-mobility-impact-brief

5) Ministry of National Education of Morocco. (2018). Evaluation interne de l'usage des technologies d'information et de communication dans les pratiques pédagogiques. Ministry of National Education of Morocco.

6) Murphy, R., \& Wyness , G. (2020). Minority Report: the impact of predicted grades on university admissions of disadvantaged groups. Centre for Education Policy and Equalising Opportunitites, UCL Institute of Education.

7) OECD. (2019). PISA 2018 Results (Volume I): What Students Know and Can Do. Paris: PISA, OECD Publishing. doi:https://doi.org/10.1787/5f07c754-en

8) ONUTICE. (2020, 04 27). Récupéré sur Taalimtice: http://www.taalimtice.ma/ONUTICE/695/\%D8\%A8\%D8\%B1\%D9\%86\%D8\%A7\%D9\%85 \%D8\%AC-\%D8\%AC\%D9\%8A\%D9\%86\%D9\%8A-\%D8\%A7\%D9\%84\%D8\%AD\%D8\% B5\%D9\%8A\%D9\%84\%D8\%A9-\%D8\%A7\%D9\%84\%D9\%88\%D8\%B7\%D9\%86\%D9\%8 A\%D8\% A9 